\title{
Hip fractures in 2016, where do we stand and have we made any progress?
}

\author{
Cyril Mauffrey $^{1}$ (D) Steven Stacey $^{1} \cdot$ Mark Hake $^{1} \cdot$ David Hak $^{1}$
}

Received: 22 February 2016/Accepted: 23 February 2016/Published online: 9 March 2016

(C) Springer-Verlag France 2016

With the baby boomers entering their 70 s, the epidemiology of hip fractures is about to change with an increase in the second peak of the bimodal distribution [1].

The so-called epidemic of hip fractures will affect a physically active population that has high expectations and longer life expectancy. Despite such anticipated changes, meaningful progress on the various multifaceted topics related to hip fractures has been scarce and the 1 -ear mortality has not changed significantly. Preventative measures such as early diagnosis/treatment of osteoporosis and fall prevention have now been implemented in most developed countries [2]. Strategies such as fast tracking of patients with hip fractures or enhanced recovery programs are now well in place $[3,4]$. Treatment options to improve fracture reduction and fixation with the use of novel implants, construct designs and fixation augmentation are being utilized and studied $[5,6]$. For elderly patients with displaced femoral neck fractures, the total hip arthroplasty remains the gold standard, providing improved functional outcomes and early return to activities.

For the young adult patients with a femoral neck fracture, several papers have been published recently, describing biomechanically sound constructs through the use of, among other strategies, medial femoral neck antiglide plating [5, 7]. The debate of timing of reduction and closed versus open reduction is still ongoing. The choice of approach for an open reduction has little bearing on the quality of reduction or functional outcomes.

Cyril Mauffrey

cyril.mauffrey@dhha.org

1 Denver Health and Hospital Authority, Englewood, CO, USA
In this issue, we have selected pertinent papers focusing on the topic of hip and intertrochanteric fractures. Our first paper from Giannoudis et al. [8] highlights that government-lead fast track streamlined initiatives implemented to improve care of elderly patients with femoral neck fractures have steadily improved the 30-day mortality of such patients.

The second paper from Hake and Goulet et al. [9] focuses on atypical femur fractures in patients receiving bisphosphonates. This is a complex problem affecting a growing population.

On the topic of hip fractures in the young, we have described tips and tricks to improve the quality of reduction and fixation of such complex injuries [10]. Finally, Matityahua et al. [11] reveal the importance of fracture reduction and fixation in valgus as this improves loading characteristics especially when sliding hip screw and plate constructs are selected.

\section{References}

1. Klop C, Welsing PM, Leufkens HG, Elders PJ, Overbeek JA, van den Bergh JP, Bijlsma JW, de Vries F (2015) The epidemiology of hip and major osteoporotic fractures in a Dutch population of community-dwelling elderly: implications for the Dutch FRAX ${ }^{\circledR}$ algorithm. PLoS ONE 10(12):e0143800

2. Farmer RP, Herbert B, Cuellar DO, Hao J, Stahel PF, Yasui R, Hak DJ, Mauffrey C (2014) Osteoporosis and the orthopaedic surgeon: basic concepts for successful co-management of patients' bone health. Int Orthop 38(8):1731-1738

3. Talboys R, Mak M, Modi N, Fanous N, Cutts S (2016) Enhanced recovery programme reduces opiate consumption in hip hemiarthroplasty. Eur J Orthop Surg Traumatol 26(2):177-181

4. Gregersen M, Damsgaard EM, Borris LC (2015) Blood transfusion and risk of infection in frail elderly after hip fracture surgery: the TRIFE randomized controlled trial. Eur J Orthop Surg Traumatol 25(6):1031-1038 
5. Ye Y, Hao J, Mauffrey C, Hammerberg EM, Stahel PF, Hak DJ (2015) Optimizing stability in femoral neck fracture fixation. Orthopedics 38(10):625-630

6. Morris K, Davies H, Wronka K (2015) Implant-related complications following hip hemiarthroplasty: a comparison of modern cemented and uncemented prostheses. Eur J Orthop Surg Traumatol 25(7):1161-1164

7. Mir H, Collinge C (2015) Application of a medial buttress plate may prevent many treatment failures seen after fixation of vertical femoral neck fractures in young adults. Med Hypotheses 84(5):429-433

8. Giannoulis D, Calori GM, Giannoudis PV (2016) Thirty-day mortality after hip fractures: has anything changed? Eur J Orthop Surg Traumatol 26(4). doi:10.1007/s00590-016-1744-4
9. Blum L, Cummings K, Goulet JA, Perdue AM, Mauffrey C, Hake ME (2016) Atypical femur fractures in patients receiving bisphosphonate therapy: etiology and management. Eur J Orthop Surg Traumatol 26(4). doi:10.1007/s00590-016-1742-6

10. Stacey S, Hak DJ, Hame M, Mauffrey C (2016) Tips and tricks for ORIF of displaced femoral neck fractures in the young adult patient. Eur J Orthop Surg Traumatol 26(4)

11. Matityahua A et al (2016) Effect of varus and valgus alignment on implant loading after proximal femur fracture fixation. Eur $\mathbf{J}$ Orthop Surg Traumatol 26(4) 